\title{
Severe Re-expansion Pulmonary Edema Induced by One-Lung Ventilation
}

\author{
Yuki Sugiyama MD PhD, Fumiko Shimizu MD, Sari Shimizu MD, Masatoshi Urasawa MD, \\ Satoshi Tanaka MD PhD, and Mikito Kawamata MD
}

\begin{abstract}
We present 2 cases of severe re-expansion pulmonary edema (RPE) after one-lung ventilation (OLV) for thoracic surgery. A 32-y-old woman with multiple lung metastases developed severe RPE after OLV during lung resection surgery. A 37-y-old man with infective endocarditis also developed severe RPE after OLV for mitral valve plasty with minimally invasive cardiac surgery. In both cases, results of a preoperative pulmonary function test and oxygenation were almost normal, and pleural effusion or pulmonary congestion was not detected in preoperative computed tomography; however, there was a possibility that subclinical lung injury existed before surgery. The levels of interleukin-8 and monocyte chemotactic protein-1, which are thought to play important roles in the development of lung injury, in bronchial secretions were extremely high after the onset of RPE. These results suggest that the pathogenesis of RPE shares, at least in part, a common pathophysiology of acute lung injury. Key words: pulmonary edema; one-lung ventilation; interleukin-8; monocyte chemotactic protein-1. [Respir Care 2015;60(8):e134-e140. (C) 2015 Daedalus Enterprises]
\end{abstract}

\section{Introduction}

Re-expansion pulmonary edema (RPE) is a life-threatening but rare complication after re-expansion of a collapsed lung. Decreased lung interstitial pressure caused by rapid expansion of a collapsed lung has been thought to be an essential factor for the development of RPE. In addition, recent animal studies have shown that cytokines and chemokines also play important roles in the occurrence of RPE. ${ }^{1,2}$ However, there are few reports showing an association of such mediators with the development of RPE in a clinical setting. Here, we report 2 patients in whom RPE occurred during surgery and in whom interleukin (IL)-8 and monocyte chemotactic protein-1 (MCP-1) levels in lung secretions were measured.

\footnotetext{
The authors are affiliated with the Department of Anesthesiology and Resuscitology, Shinshu University School of Medicine, Matsumoto, Nagano, Japan.
}

The authors have disclosed no conflicts of interest.

Correspondence: Yuki Sugiyama MD PhD, Department of Anesthesiology and Resuscitology, Shinshu University School of Medicine, 3-1-1 Asahi, Matsumoto, Nagano 390-8621, Japan. E-mail: ysugiyama@ shinshu-u.ac.jp.

DOI: $10.4187 /$ respcare. 03759

\section{Case Reports}

\section{Case 1}

A 32-y-old woman with lung cancer (in the right lower lobe and left lingual lobe) that metastasized from rectal cancer was scheduled for bilateral video-assisted thoracoscopic surgery for lung resection. She had undergone resection of the rectum for rectal cancer 6 months previously. Adjuvant chemotherapy with oxaliplatin and capecitabine was started 5 months before lung surgery, and 5 cycles of chemotherapy were completed. Preoperative pulmonary function testing revealed normal values, with $\mathrm{FEV}_{1} / \mathrm{FVC}$ of 0.81 and $\mathrm{FVC}$ of $108 \%$ of predicted, and computed tomography revealed no abnormality other than the tumor shadow. Results of other laboratory tests were unremarkable.

When the patient was admitted to the operating room, her blood pressure was $122 / 60 \mathrm{~mm} \mathrm{Hg}$, heart rate was 70 beats/min, and $\mathrm{S}_{\mathrm{pO}_{2}}$ on room air was $100 \%$. After insertion of an epidural catheter at the thoracic 5-6 interspace, anesthesia (propofol and remifentanil) was administered. After muscle relaxation had been achieved with rocuronium, the patient was intubated with a $35 \mathrm{Fr}$ left double-lumen endotracheal tube. Anesthesia was main- 
A

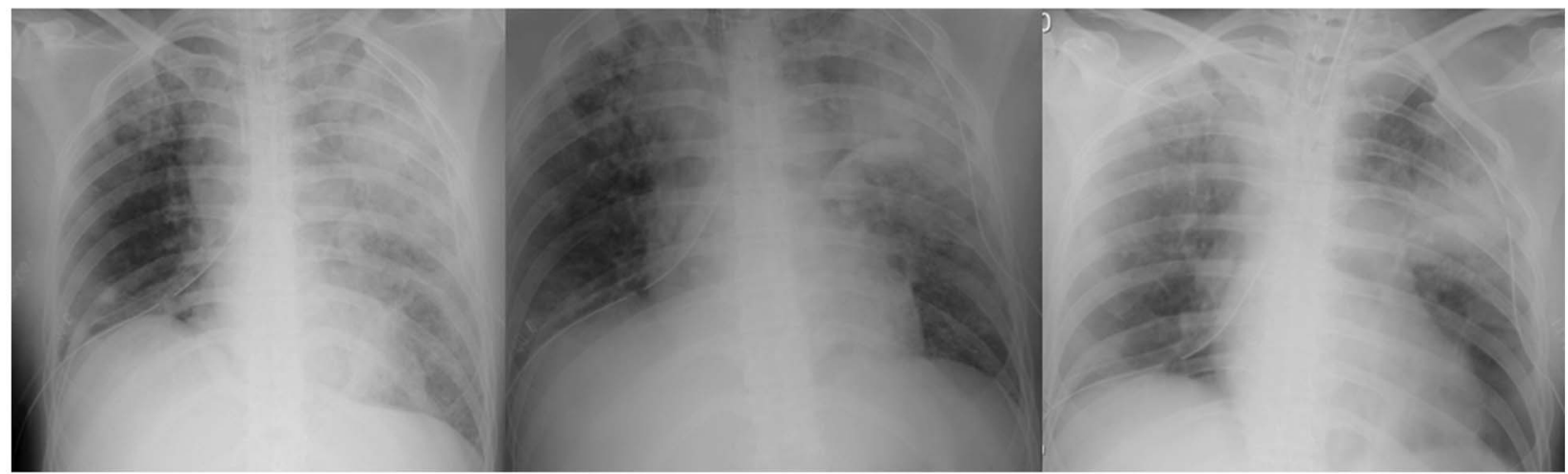

$4 \mathrm{~h}$

B

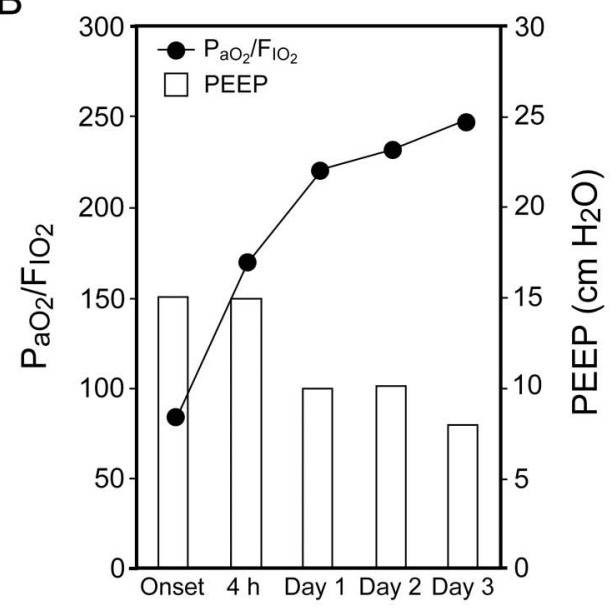

$24 \mathrm{~h}$

C

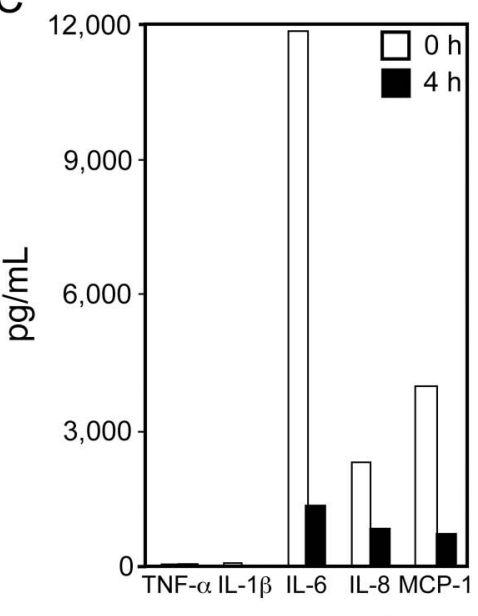

Day 2

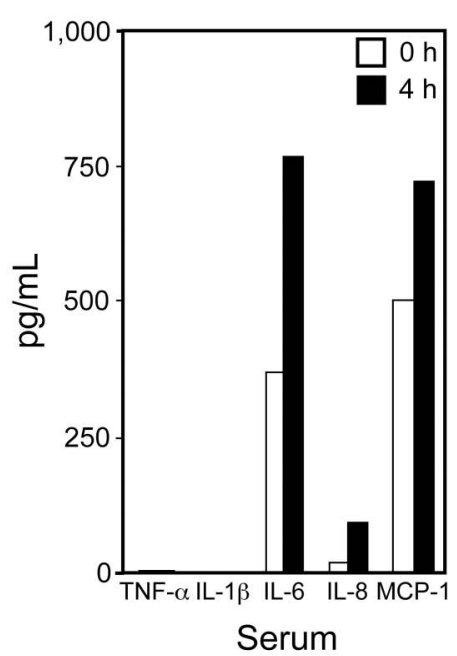

Fig. 1. Clinical and laboratory findings in Case 1. A: Postoperative chest radiographs. Alveolar infiltrates in both lungs are shown. $\mathrm{B}: \mathrm{P}_{\mathrm{aO}} / \mathrm{F}_{\mathrm{IO}_{2}}$ and PEEP after the onset of re-expansion pulmonary edema (RPE). C: Levels of cytokines and chemokine. The left panel shows mediator levels in bronchial secretions, and the right panel shows mediator levels in serum. The normal serum levels of cytokines and chemokine are as follows: interleukin (IL)-1 $\beta,<10 \mathrm{pg} / \mathrm{mL}$; IL-6, $<4 \mathrm{pg} / \mathrm{mL}$; IL-8, $<2 \mathrm{pg} / \mathrm{mL}$; tumor necrosis factor alpha $(\mathrm{TNF}-\alpha),<0.2-2.8 \mathrm{pg} / \mathrm{mL}$; and monocyte chemotactic protein-1 (MCP-1), $<149 \mathrm{pg} / \mathrm{mL}$. MCP-1 at $>4,000 \mathrm{pg} / \mathrm{mL}$ is above the limit of detection. In Case 1 , the mediator levels at $24 \mathrm{~h}$ after RPE onset in bronchial secretions and serum were not measured because bronchial secretions were not obtained. The MCP-1 level in bronchial secretions at $4 \mathrm{~h}$ after RPE onset was above $4,000 \mathrm{pg} / \mathrm{mL}$.

tained with propofol and remifentanil and with intermittent thoracic epidural administration of ropivacaine.

Surgery was started in a right lateral position, and rightlung ventilation was initiated. The patient was ventilated at a peak inspiratory pressure (PIP) of $22 \mathrm{~cm} \mathrm{H}_{2} \mathrm{O}$, and $\mathrm{S}_{\mathrm{pO}_{2}}$ was maintained at $98-100 \%$ with an $\mathrm{F}_{\mathrm{IO}_{2}}$ of 1.0 . Segmentectomy of S3 and partial resection of the lingula and $\mathrm{S} 10$ of the left lung were completed uneventfully. The left lung was then expanded by manual ventilation with a PIP of $25 \mathrm{~cm} \mathrm{H}_{2} \mathrm{O}$. The duration of right-lung ventilation was 264 min.

After postural change to a left lateral position, a right lower lobectomy was performed. Left-lung ventilation was started $\sim 30$ min after re-expansion at a PIP of $30 \mathrm{~cm} \mathrm{H}_{2} \mathrm{O}$.
At $\sim 1 \mathrm{~h}$ after starting left-lung ventilation, bubbly secretions spilled out from the left bronchus, and $\mathrm{S}_{\mathrm{pO}_{2}}$ decreased from $99 \%$ to $82 \%$ with an $\mathrm{F}_{\mathrm{IO}_{2}}$ of 1.0 in $1 \mathrm{~h}$. Because of hypoxemia, partial resection of the right upper lobe was cancelled. The duration of left-lung ventilation was $125 \mathrm{~min}$. After bilateral-lung ventilation was started, arterial blood gas analysis showed $\mathrm{P}_{\mathrm{aO}_{2}}$ of $84 \mathrm{~mm} \mathrm{Hg}, \mathrm{P}_{\mathrm{aCO}_{2}}$ of $60 \mathrm{~mm} \mathrm{Hg}$, and $\mathrm{pH} 7.22$ with an $\mathrm{F}_{\mathrm{IO}_{2}}$ of 1.0.

A postoperative chest radiograph showed diffusely spread infiltrates, especially in the left lung (Fig. 1A), without any symptoms of heart failure, and a diagnosis of RPE was made. The patient was transferred to the ICU, where she was ventilated at a PIP of $22 \mathrm{~cm} \mathrm{H}_{2} \mathrm{O}$ and PEEP of $15 \mathrm{~cm} \mathrm{H}_{2} \mathrm{O}$. Four h after the onset of RPE, secretions 
from the left bronchus greatly decreased, and oxygenation improved, showing a $\mathrm{P}_{\mathrm{aO}_{2}}$ of $119 \mathrm{~mm} \mathrm{Hg}$ with an $\mathrm{F}_{\mathrm{IO}_{2}}$ of 0.7 (Fig. 1B). Ten $\mathrm{h}$ after the onset of RPE, secretions from the left bronchus stopped. On day 2 after ICU admission, a chest radiograph showed improvement of alveolar infiltrates in the right lung, but the diffusely spread infiltrates in the left lung remained. On day 6 after ICU admission, she was extubated and discharged from the ICU. Alveolar infiltration had almost disappeared 1 month after surgery. She was discharged from our hospital 2 months after surgery.

Analysis of bronchial secretions and serum by an enzyme-linked immunosorbent assay revealed that the IL-8 and MCP-1 levels in bronchial secretions were extremely high at the onset of RPE (Fig. 1C). However, $4 \mathrm{~h}$ after the onset of RPE, bronchial mediator levels were decreased. In contrast to bronchial secretions, the levels of these mediators in serum were increased $4 \mathrm{~h}$ after the onset of RPE compared with those at the onset of RPE. Tumor necrosis factor alpha and IL- $1 \beta$ levels were close to normal levels in both serum and bronchial secretions.

\section{Case 2}

A 37-y-old man with fever, exertional dyspnea, and joint pain caused by infective endocarditis was scheduled for mitral valve plasty with minimally invasive cardiac surgery. A transthoracic echocardiogram showed $17 \mathrm{~mm}$ $\times 10 \mathrm{~mm}$ vegetation in the anterior mitral leaflet with severe mitral regurgitation as a result of $\mathrm{A} 2$ and $\mathrm{A} 3$ prolapse, normal left ventricular function with an ejection fraction of $74 \%$, and a tricuspid regurgitation pressure gradient of $27 \mathrm{~mm} \mathrm{Hg}$. Laboratory tests showed mild hypoproteinemia $(6.3 \mathrm{~g} / \mathrm{dL})$, hypoalbuminemia $(2.7 \mathrm{~g} / \mathrm{dL})$, an increase in C-reactive protein $(6.1 \mathrm{mg} / \mathrm{dL})$, and a mild increase in brain natriuretic peptide $(58 \mathrm{pg} / \mathrm{mL})$. Ampicillin and gentamicin were administered intravenously after Streptococcus had been detected in a blood culture. Preoperative pulmonary function testing revealed almost normal values with $\mathrm{FEV}_{1} / \mathrm{FVC}$ of 0.92 and an $\mathrm{FVC}$ of $79 \%$ of predicted. Pleural effusion and pulmonary congestion were not detected in lung computed tomography.

When the patient was admitted to the operating room, his blood pressure was $111 / 65 \mathrm{~mm} \mathrm{Hg}$, heart rate was 94 beats/min, and $\mathrm{S}_{\mathrm{pO}_{2}}$ on room air was $99 \%$. Propofol and remifentanil were administered. After muscle relaxation had been achieved with rocuronium, the patient was intubated with a $37 \mathrm{Fr}$ left double-lumen endotracheal tube. Anesthesia was maintained with sevoflurane, propofol, fentanyl, and remifentanil. Methylprednisolone $(1,000 \mathrm{mg})$ was administered before cardiopulmonary bypass.

Minimally invasive cardiac surgery was performed with a right thoracotomy, and left-lung ventilation was started. The patient was ventilated at a PIP of $22 \mathrm{~cm} \mathrm{H}_{2} \mathrm{O}$ before cardiopulmonary bypass. During this period, arterial blood gas analysis showed a $\mathrm{P}_{\mathrm{aO}_{2}}$ of $233 \mathrm{~mm} \mathrm{Hg}, \mathrm{P}_{\mathrm{aCO}_{2}}$ of $38 \mathrm{~mm} \mathrm{Hg}$, and $\mathrm{pH} 7.45$ with an $\mathrm{F}_{\mathrm{IO}_{2}}$ of 1.0. After cardiopulmonary bypass had been established, ventilation was stopped. The duration of left-lung ventilation before cardiopulmonary bypass was $59 \mathrm{~min}$. Mitral valve plasty was performed under mild hypothermia (minimum rectal temperature of $34.1^{\circ} \mathrm{C}$ ) with cardiopulmonary bypass. Cardiopulmonary bypass time was $266 \mathrm{~min}$, and weaning from cardiopulmonary bypass with restart of left-lung ventilation was achieved uneventfully with dopamine ( $3 \mu \mathrm{g} / \mathrm{kg} / \mathrm{min})$ and dobutamine $(3 \mu \mathrm{g} / \mathrm{kg} / \mathrm{min})$. An intraoperative transesophageal echocardiogram after mitral valve plasty showed normal wall motion and no mitral regurgitation or mitral valve stenosis. Before closing the chest, the right lung was expanded by manual ventilation and ventilated at a PIP of $20 \mathrm{~cm} \mathrm{H}_{2} \mathrm{O}$ and PEEP of $6 \mathrm{~cm} \mathrm{H}_{2} \mathrm{O}$. After bilateral-lung ventilation, arterial blood gas analysis showed a $\mathrm{P}_{\mathrm{aO}_{2}}$ of $262 \mathrm{~mm} \mathrm{Hg}, \mathrm{P}_{\mathrm{aCO}_{2}}$ of $38 \mathrm{~mm} \mathrm{Hg}$, and $\mathrm{pH} 7.45$ with an $\mathrm{F}_{\mathrm{IO}_{2}}$ of 1.0. The duration of right-lung collapse was 285 min.

At $\sim 40$ min after re-expansion of the right lung, a large amount of serous bronchial secretions spilled out from the right bronchus without any symptoms of heart failure. More than $1,000 \mathrm{~mL}$ of bronchial secretions was aspirated in $30 \mathrm{~min}$ and continued to spill out. A postoperative chest radiograph showed diffusely spread pulmonary infiltrates only in the right lung (Fig. 2A). A diagnosis of RPE was made, and the patient was transferred to the ICU. He was ventilated at a tidal volume of $550 \mathrm{~mL}$ and PEEP of $12 \mathrm{~cm} \mathrm{H} \mathrm{H}_{2} \mathrm{O}$, and arterial blood gas analysis showed $\mathrm{P}_{\mathrm{aO}_{2}}$ of $167 \mathrm{~mm} \mathrm{Hg}$ with an $\mathrm{F}_{\mathrm{IO}_{2}}$ of 1.0. Four h after the onset of RPE, oxygenation was still poor, showing a $\mathrm{P}_{\mathrm{aO}_{2}}$ of $96 \mathrm{~mm} \mathrm{Hg}$ with an $\mathrm{F}_{\mathrm{IO}_{2}}$ of 0.7 (Fig. 2B). Bronchial secretions continued at $\sim 1,500 \mathrm{~mL}$ over $12 \mathrm{~h}$. Twenty-four $\mathrm{h}$ after the onset of RPE, the amount of bronchial secretions gradually decreased to $\sim 800 \mathrm{~mL}$ over $12 \mathrm{~h}$, and oxygenation slightly improved, showing a $\mathrm{P}_{\mathrm{aO}_{2}}$ of $72 \mathrm{~mm} \mathrm{Hg}$ on a PEEP of $10 \mathrm{~cm} \mathrm{H}_{2} \mathrm{O}$ with an $\mathrm{F}_{\mathrm{IO}_{2}}$ of 0.3 . On day 4 after ICU admission, he was extubated. Alveolar infiltration had almost disappeared 1 month after surgery. He was discharged from our hospital 6 weeks after surgery.

Analysis of bronchial secretions and serum by an enzyme-linked immunosorbent assay revealed that the IL-8 and MCP-1 levels in bronchial secretions were not extremely high at the onset of RPE (Fig. 2C). However, at 4 and $24 \mathrm{~h}$ after the onset of RPE, the levels of these mediators were greatly increased. In contrast to bronchial secretions, the levels of these mediators in serum were not changed during the 24-h period after the onset of RPE. Tumor necrosis factor alpha and IL- $1 \beta$ levels were close to normal levels in both serum and bronchial secretions. 
A

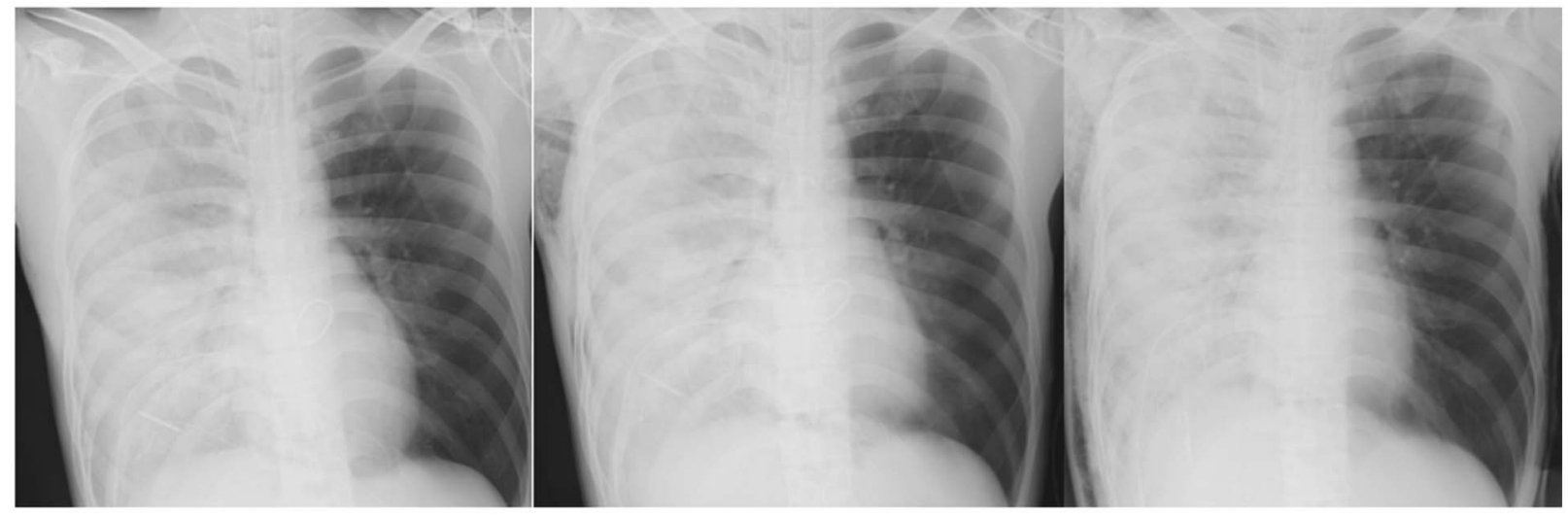

$4 \mathrm{~h}$

B

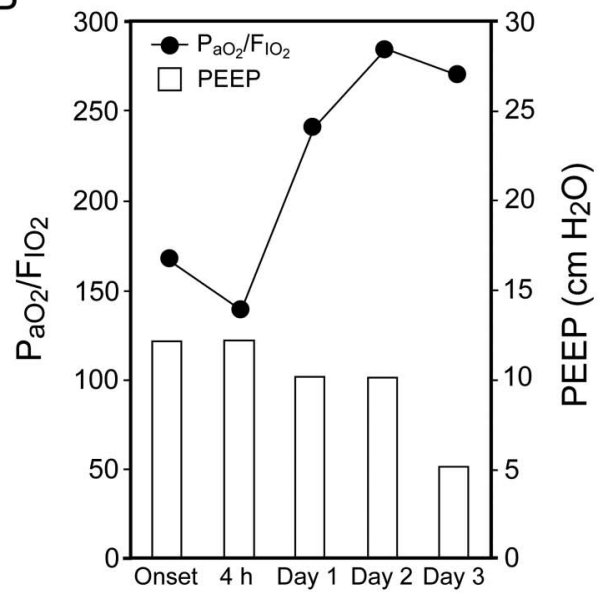

$24 \mathrm{~h}$

C

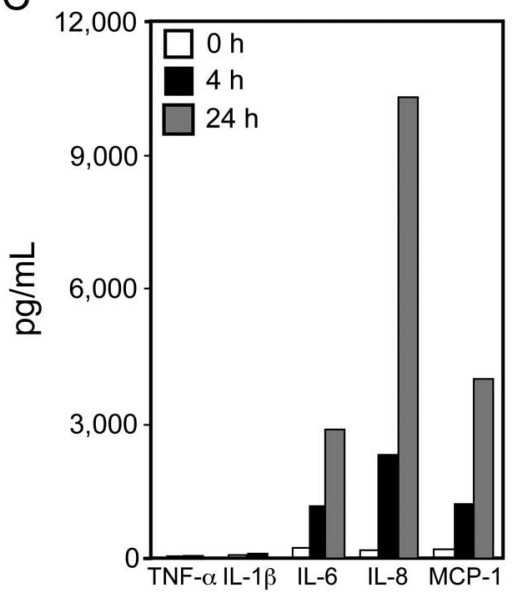

Bronchial secretions
Day 2

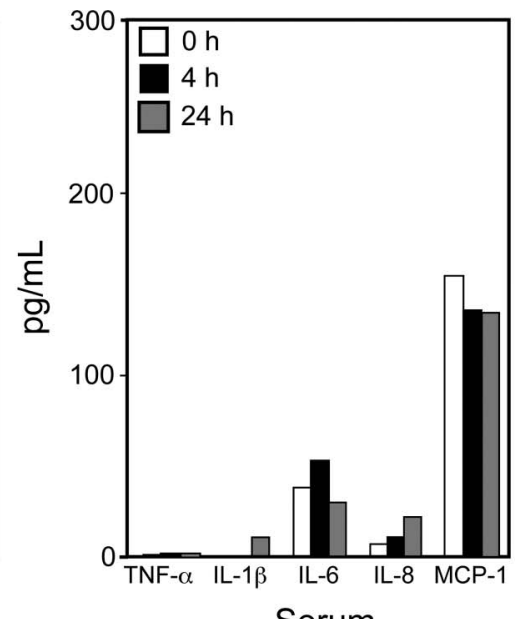

Fig. 2. Clinical and laboratory findings in Case 2. A: Postoperative chest radiographs. Diffusely spread pulmonary infiltrate only in the right lung is shown. $\mathrm{B}: \mathrm{P}_{\mathrm{aO}_{2}} / \mathrm{F}_{\mathrm{IO}_{2}}$ and PEEP after the onset of re-expansion pulmonary edema (RPE). C: Levels of cytokines and chemokine. The left panel shows mediator levels in bronchial secretions, and the right panel shows mediator levels in serum. The normal serum levels of cytokines and chemokine are as follows: interleukin (IL)-1 $\beta,<10 \mathrm{pg} / \mathrm{mL}$; IL-6, $<4 \mathrm{pg} / \mathrm{mL}$; IL-8, $<2 \mathrm{pg} / \mathrm{mL}$; tumor necrosis factor alpha $(\mathrm{TNF}-\alpha),<0.2-2.8 \mathrm{pg} / \mathrm{mL}$; and monocyte chemotactic protein-1 (MCP-1), $<149 \mathrm{pg} / \mathrm{mL}$. MCP-1 at $>4,000 \mathrm{pg} / \mathrm{mL}$ is above the limit of detection. The MCP-1 level in bronchial secretions at $24 \mathrm{~h}$ after RPE onset was above 4,000 pg/mL.

\section{Discussion}

RPE is a well-known complication after drainage of spontaneous pneumothorax. It has been reported that lungcollapse duration is not relevant to RPE severity in a clinical setting. ${ }^{3}$ RPE occurred despite a relatively short lungcollapse duration, ${ }^{4,5}$ suggesting that RPE is likely to occur following re-expansion of a collapsed lung after one-lung ventilation $(\mathrm{OLV})$ in patients undergoing video-assisted thoracoscopic surgery. However, it was reported that the incidence of RPE associated with video-assisted thoracoscopic surgery was only $0.15 \%$, even though video-assisted thoracoscopic surgery for treatment of spontaneous pneumothorax was included. ${ }^{6}$ Indeed, despite the routine use of OLV in thoracic surgery, there have been only a few reports of RPE over the past several decades (Table 1).,5,7-11 Importantly, in all of these patients previously reported, lung injury and/or lung diseases had already existed before surgery was performed. Thus, it is likely that RPE after OLV is very rare and can occur only in patients in whom lung injury already coexists.

In our 2 patients, lung injury was not revealed before surgery, and preoperative pulmonary function and oxygenation were normal. However, subclinical lung injury might have existed before surgery. In Case 1, the patient had multiple metastatic lung cancer and received adjuvant chemotherapy with oxaliplatin, which has been reported to have pulmonary toxicity, ${ }^{12-14}$ causing pneumonia, diffuse 
Severe Re-expansion Pulmonary Edema

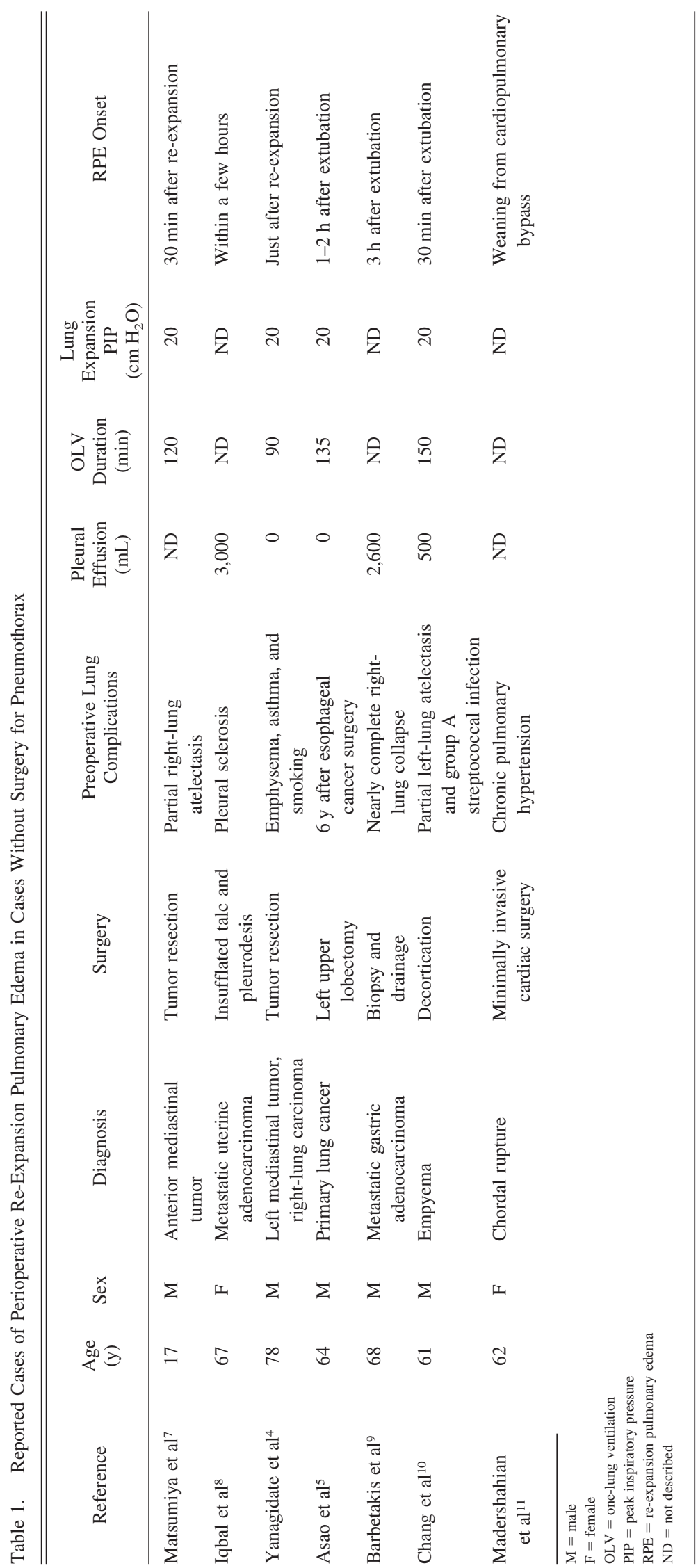


alveolar damage, and nonspecific interstitial lung disease. In Case 2, the patient complained of exertional dyspnea caused by acute severe mitral regurgitation. Severe mitral regurgitation is known to be the main cause of unilateral pulmonary edema, and most cases occur in the right lung because the regurgitant flow is directed to the right pulmonary vein, ${ }^{15-17}$ possibly resulting in right-lung injury. In addition to these preoperative potential lung injuries, subsequent lung damage by re-expansion during surgery might have led to severe RPE after OLV. In Case 1, the collapsed lung was ventilated with a PIP of $30 \mathrm{~cm} \mathrm{H}_{2} \mathrm{O}$. This relatively high PIP may have exacerbated the damage of the lung that was already injured by RPE.

IL-8 and MCP-1, which are chemotactic factors for monocytes and neutrophils, respectively, produced mainly by vascular endothelial cells of the lungs, ${ }^{18,19}$ are thought to be involved in the development of acute lung injury and inflammation. ${ }^{20-23}$ The levels of IL-8 and MCP-1 in bronchoalveolar lavage fluid have been reported to correlate with clinical severity and mortality in patients with acute lung injury. ${ }^{23}$

Regarding the pathogenesis of RPE, the pulmonary microvascular endothelium is mechanically destroyed immediately after the collapsed lung has been expanded, and ischemia-reperfusion injury subsequently occurs in the injured pulmonary microvessels. ${ }^{24}$ Such mechanical and ischemic injuries are thought to result in secretion of IL-8 and MCP-1, leading to increased permeability of pulmonary microvessels. From findings based on previous animal experiments, ${ }^{1,2}$ IL-8 and MCP-1 are also thought to be involved in the development of RPE. It has also been reported that IL-8 levels in bronchial secretions at RPE onset are high in patients with RPE due to pneumothorax in which the lungs were collapsed for $>1$ week. ${ }^{25,26}$ Taken together with the previous reports, IL- 8 and MCP-1 may be involved in the occurrence and development of RPE even after OLV in humans.

In Case 1, the IL-8 and MCP-1 levels in bronchial secretions at the onset of RPE were extremely high and were dramatically decreased $4 \mathrm{~h}$ after the onset of RPE, consistent with an increase in $\mathrm{P}_{\mathrm{aO}} / \mathrm{F}_{\mathrm{IO}_{2}}$. However, the serum levels of these mediators at $4 \mathrm{~h}$ after the onset of RPE were increased compared with those at the onset of RPE (Fig. 1C). These differences between the time courses of serum and bronchial secretion levels may indicate that the mediators released from the re-expanded lung exacerbated alveolar and capillary damage and leaked into the circulation.

The levels of these mediators in bronchial secretions in Case 2 gradually increased after RPE onset. The effect of methylprednisolone administration before cardiopulmonary bypass, the influence of cardiopulmonary bypass, and dilution by a large amount of bronchial secretions may have changed the mediator levels in bronchial secretions during the time course of RPE. Finally, the IL- 8 and MCP-1 levels in bronchial secretions at $24 \mathrm{~h}$ after RPE onset were extremely high in Case 2, suggesting that IL-8 and MCP-1 were also involved in the pathogenesis and/or development of RPE. In fact, alveolar infiltrates did not improve over a period of $24 \mathrm{~h}$ (Fig. 2A). However, oxygenation was improved in Case 2 within $24 \mathrm{~h}$. This discrepancy is probably due to the improvement in the ventilation/perfusion ratio. In Case 2, RPE occurred only in the right lung, and we therefore considered that perfusion shift from the right lung to the left lung occurred and oxygenation improved.

The serum levels of tumor necrosis factor alpha and IL-1 $\beta$, which are produced by many types of immune cells in response to systemic injury and inflammation, were low in both cases, suggesting that the systemic inflammation and reaction caused by surgical injury were not critical. In addition, it was reported that tumor necrosis factor alpha and IL- $1 \beta$ levels in bronchial secretions at RPE onset were not elevated in a pneumothorax case. ${ }^{25}$ Taken together, the results suggest that tumor necrosis factor alpha and IL- $1 \beta$ were not involved in the occurrence and development of RPE after OLV in our 2 patients.

IL-6 is thought to be a nonspecific biomarker associated with various diseases, including lung injury, and has also been shown to predict the risk of death in patients with acute lung inflammation. ${ }^{27}$ We considered that IL-6 reflected the severity of lung injury associated with RPE in our 2 patients.

Preoperatively existing and/or potential lung injury is an important risk factor for occurrence of RPE after OLV. However, youth is a risk factor for RPE in patients with spontaneous pneumothorax. ${ }^{3}$ The incidence of RPE in a 20-39-y age group was shown to be significantly higher than that in a $>40-y$ age group. Our patients were also young, consistent with previous report in which patients with spontaneous pneumothorax were analyzed. Thus, youth is also a risk factor of RPE occurrence after OLV during surgery. In addition, $>30 \%$ of a collapsed lung field is another risk factor for RPE in patients with spontaneous pneumothorax, ${ }^{3}$ and the incidence of RPE is higher when the collapsed lung is larger. ${ }^{28}$ Because OLV was carried out in our 2 patients, almost $50 \%$ of the lung was collapsed. Thus, OLV itself may be a risk factor for RPE in patients who have preoperative lung injury and complications.

In conclusion, RPE occurred during surgery in 2 patients undergoing OLV, in whom subclinical lung injury may have been present before surgery, and their IL- 8 and MCP-1 bronchial secretion levels were greatly increased after RPE onset, suggesting that the pathogenesis of RPE shared a common pathophysiology of acute lung injury. Further studies, including bronchoalveolar lavage and biopsy throughout the clinical course of RPE, are needed to 


\section{Severe Re-expansion Pulmonary Edema}

elucidate the mechanism and to prevent the development of RPE.

\section{ACKNOWLEDGMENTS}

We thank Prof. Tomoyuki Kawamata (Wakayama Medical University, Wakayama, Japan) for helpful comments.

\section{REFERENCES}

1. Nakamura M, Fujishima S, Sawafuji M, Ishizaka A, Oguma T, Soejima K, et al. Importance of interleukin- 8 in the development of reexpansion lung injury in rabbits. Am J Respir Crit Care Med 2000;161(3 Pt 1):1030-1036.

2. Sakao Y, Kajikawa O, Martin TR, Nakahara Y, Hadden WA 3rd, Harmon CL, Miller EJ. Association of IL-8 and MCP-1 with the development of reexpansion pulmonary edema in rabbits. Ann Thorac Surg 2001;71(6):1825-1832.

3. Matsuura Y, Nomimura T, Murakami H, Matsushima T, Kakehashi M, Kajihara H. Clinical analysis of reexpansion pulmonary edema. Chest 1991;100(6):1562-1566.

4. Yanagidate F, Dohi S, Hamaya Y, Tsujito T. Reexpansion pulmonary edema after thoracoscopic mediastinal tumor resection. Anesth Analg 2001;92(6):1416-1417.

5. Asao Y, Kobayashi M, Tsubaki N, Kobayashi O, Uehara K. [A case of re-expansion pulmonary edema after one lung ventilation for the radical operation of lung cancer]. Masui 2003;52(2):154-157. Article in Japanese.

6. Yim AP, Liu HP. Complications and failures of video-assisted thoracic surgery: experience from two centers in Asia. Ann Thorac Surg 1996;61(2):538-541.

7. Matsumiya N, Dohi S, Kimura T, Naito H. Reexpansion pulmonary edema after mediastinal tumor removal. Anesth Analg 1991;73(5): 646-648.

8. Iqbal M, Multz AS, Rossoff LJ, Lackner RP. Reexpansion pulmonary edema after VATS successfully treated with continuous positive airway pressure. Ann Thorac Surg 2000;70(2):669-671.

9. Barbetakis N, Samanidis G, Paliouras D, Tsilikas C. Re-expansion pulmonary edema following video-assisted thoracic surgery for recurrent malignant pleural effusion. Interact Cardiovasc Thorac Surg 2008;7(3):532-534.

10. Chang CY, Hung MH, Chang HC, Chan KC, Chen HY, Fan SZ, Lin TY. Delayed onset of contralateral pulmonary edema following reexpansion pulmonary edema of a collapsed lung after video-assisted thoracoscopic surgery. Acta Anaesthesiol Taiwan 2009;47(2):87-91.

11. Madershahian N, Wippermann J, Sindhu D, Wahlers T. Unilateral re-expansion pulmonary edema: a rare complication following onelung ventilation for minimal invasive mitral valve reconstruction. J Card Surg 2009;24(6):693-694.

12. Watkins J, Slade JH, Phan A, Eng C, Weissferdt A, Overman MJ. Fatal diffuse alveolar damage associated with oxaliplatin administration. Clin Colorectal Cancer 2011;10(3):198-202.

13. Homma T, Kurokawa M, Yamamoto Y, Matsukura S, Ieki K, Suzuki $\mathrm{S}$, et al. Oxaliplatin-induced lung injury with allergic reaction. Chin J Cancer Res 2011;23(3):232-235.
14. Wilcox BE, Ryu JH, Kalra S. Exacerbation of pre-existing interstitial lung disease after oxaliplatin therapy: a report of three cases. Respir Med 2008;102(2):273-279.

15. Salinas P, Martín-Reyes R, Peinado R, Ramírez U. Unilateral pulmonary edema and shock: a diagnostic challenge. Intensive Care Med 2009;35(11):2000-2001.

16. Attias D, Mansencal N, Auvert B, Vieillard-Baron A, Delos A, Lacombe $\mathrm{P}$, et al. Prevalence, characteristics, and outcomes of patients presenting with cardiogenic unilateral pulmonary edema. Circulation 2010;122(11):1109-1115.

17. Warraich HJ, Bhatti UA, Shahul S, Pinto D, Liu D, Matyal R, Mahmood F. Unilateral pulmonary edema secondary to mitral valve perforation. Circulation 2011;124(18):1994-1995.

18. Murugesan G, Sandhya Rani MR, Gerber CE, Mukhopadhyay C, Ransohoff RM, Chisolm GM, Kottke-Marchant K. Lysophosphatidylcholine regulates human microvascular endothelial cell expression of chemokines. J Mol Cell Cardiol 2003;35(11):1375-1384.

19. Mukaida N, Harada A, Matsushima K. Interleukin-8 (IL-8) and monocyte chemotactic and activating factor (MCAF/MCP-1), chemokines essentially involved in inflammatory and immune reactions. Cytokine Growth Factor Rev 1998;9(1):9-23.

20. de Boer WI, Sont JK, van Schadewijk A, Stolk J, van Krieken JH, Hiemstra PS. Monocyte chemoattractant protein 1, interleukin 8, and chronic airways inflammation in COPD. J Pathol 2000;190(5):619626.

21. Car BD, Meloni F, Luisetti M, Semenzato G, Gialdroni-Grassi G, Walz A. Elevated IL-8 and MCP-1 in the bronchoalveolar lavage fluid of patients with idiopathic pulmonary fibrosis and pulmonary sarcoidosis. Am J Respir Crit Care Med 1994;149(3 Pt 1):655-659.

22. Meloni F, Cascina A, Paschetto E, Marone Bianco A, Morosini M, Pellegrini $\mathrm{C}$, et al. Monocyte chemoattractant protein-1 levels in bronchoalveolar lavage fluid of lung-transplanted patients treated with tacrolimus as rescue treatment for refractory acute rejection. Transplant Proc 2003;35(4):1523-1526.

23. Lin WC, Lin CF, Chen CL, Chen CW, Lin YS. Prediction of outcome in patients with acute respiratory distress syndrome by bronchoalveolar lavage inflammatory mediators. Exp Biol Med 2010; 235(1):57-65.

24. Sohara Y. Reexpansion pulmonary edema. Ann Thorac Cardiovasc Surg 2008;14(4):205-209.

25. Nakamura H, Ishizaka A, Sawafuji M, Urano T, Fujishima S, Sakamaki F, et al. Elevated levels of interleukin-8 and leukotriene B4 in pulmonary edema fluid of a patient with reexpansion pulmonary edema. Am J Respir Crit Care Med 1994;149(4 Pt 1):1037-1040.

26. Suzuki S, Niikawa H, Shibuya J, Hosaka T, Maeda S, Suzuki T, Handa M. Analysis of edema fluids and histologic features of the lung in reexpansion pulmonary edema during video-assisted thoracoscopic surgery. J Thorac Cardiovasc Surg 2002;123(2):387-389.

27. Parsons PE, Eisner MD, Thompson BT, Matthay MA, Ancukiewicz $\mathrm{M}$, Bernard GR, et al. Lower tidal volume ventilation and plasma cytokine markers of inflammation in patients with acute lung injury. Crit Care Med 2005;33(1):1-6; discussion 230-232.

28. Yoon JS, Suh JH, Choi SY, Kwon JB, Lee BY, Lee SH, et al. Risk factors for the development of reexpansion pulmonary edema in patients with spontaneous pneumothorax. J Cardiothorac Surg 2013; $8: 164$. 